\title{
1 Modeling Noise and Lease Soft Costs Improves Wind Farm Design and
}

\section{Cost-of-Energy Predictions}

3 Le Chen ${ }^{a}$, Chris Harding ${ }^{b}$, Anupam Sharma ${ }^{c}$, Erin MacDonald ${ }^{\mathrm{d}^{*}}$

$4 \quad$ a Mountain View, CA, USA, chenle86@gmail.com

5 b Department of Geological and Atmospheric Sciences, Iowa State University, Ames, IA, USA charding@iastate.edu

6 c Department of Aerospace Engineering, Iowa State University, Ames, IA, USA sharma@iastate.edu

7 d Department of Mechanical Engineering, Stanford University, Stanford, CA, USA erinmacd@stanford.edu

$8 *$ Corresponding author. E-mail address: erinmacd@stanford.edu

9 Abstract

The Department of Energy uses the metric Cost-of-Energy to assess the financial

11 viability of wind farms. Non-hardware costs, termed soft costs, make up approximately $21 \%$

12 of total cost for a land-based farm, yet are only represented with general assumptions in

13 models of Cost-of-Energy. This work replaces these assumptions with a probabilistic model

14 of the costs of land lease and noise disturbance compensation, which is incorporated into a

15 wind-farm-layout-optimization-under-uncertainty model. These realistic representations

16 are applied to an Iowa land area with real land boundaries and house locations to

17 accentuate the challenges of accommodating landowners. The paper also investigates and

18 removes a common but unnecessary term that overestimates cost-savings from installing

19 multiple turbines. These three contributions combine to produce COE estimates in-line with

20 industry data, replacing "soft" assumptions with specific parameters, identify noise and risk

21 concerns prohibitive to the development of profitable wind farm. The model predicts COEs

22 remarkably close to real-world costs. Wind energy policy-makers can use this model to

23 promote new areas of soft-cost-focused research. 
25 Keywords: Wind Farm Layout Optimization; Cost-of-Energy; Soft Costs; Optimization

26 under Uncertainty; Land Lease Cost; Noise Disturbance Compensation

\section{$27 \quad 1$ Introduction}

28 The Department of Energy (DOE) promotes research and policies that investigate

29 alternative renewable energy technologies to alleviate U.S. dependency on coal, oil, and

30 natural gas (Office of Energy Efficiency and Renewable Energy, 2015a). Cost-Of-Energy

31 (COE), or MWH of annualized cost divided by energy output per year, offers a universal

32 metric to compare the competitiveness of different power-generation approaches (U.S.

33 Energy Information Administration, 2014). By far, the majority of research in renewable

34 energy technology focuses on decreasing $\mathrm{COE}$ to a level comparable with traditional fuel

35 sources, via improvements in technology and/or hardware-related costs. COE is used as a

36 metric in a variety of modeling studies, including hybrid energy systems, for example see

37 (Lambert et al, 2006; Katsigiannis et al., 2012). Recently, the DOE has initiated programs

38 that aim to reduce the soft costs of renewable energy. For example, the SunShot Initiative

39 (Office of Energy Efficient and Renewable Energy, 2015b), which aims to make solar energy

40 cost-competitive with other forms of energy by the end of the decade, collaborates with

41 industry and research institutes to reduce soft costs for residential solar power installation.

42 In just four years, this program has funded more than 350 projects to make the solar energy

43 resources more affordable and accessible for Americans. 
The first contribution of this paper is a nuanced modeling approach to wind energy

45 soft costs which, even though they amount to approximately $21 \%$ of a wind farm's

46 annualized costs, have received much less research attention. This $21 \%$ calculation comes

47 from the application of the enhanced cost model developed by the authors (Chen and

48 MacDonald, 2014) which is based on the Wind Turbine Design Cost and Scaling Model

49 (Fingersh et al., 2006) by National Renewable Energy Laboratory (NREL) and the Turbine

50 System Cost Report from Lawrence Berkeley National Laboratory (Bolinger and Wise,

51 2011). This paper enhances this existing work with a detailed investigation and

52 probabilistic modeling of two major soft costs in wind farm projects: the costs of landowner

53 acquisition (land lease costs) as discussed in the authors' previous work (Chen, 2013; Chen

54 and MacDonald, 2015, 2013), and noise disturbance compensation-an important

55 contribution of this work, explained in detail in Section 2.4. Noise not only annoys

56 landowners, but may also induce health issues (Dai et al., 2015), which makes the

57 consideration of noise disturbance compensation a necessity. The second contribution of

58 this paper is the application of this work to a real plot of land in Story County, Iowa. The

59 cleaning and coding of the GIS parcel data is explained in Section 2.1, and weblink is

60 provided to the cleaned parcel data so that other researchers can use it in their modeling as

61 well. The third contribution of this paper is the investigation and subsequent removal of the

62 economies-of-scale term used in previous research to model the reduction in turbine costs

63 when more than one is installed, detailed in Section 2.3. In the early-development stages of

64 commercial wind projects, developers approach landowners for permission to build

65 turbines on their land in exchange for monetary compensation. In a large-scale farmland

66 project, developers can approach over 100 individual landowners. Developers must make 
67 important and expensive decisions, such as placing equipment orders or obtaining funding

68 from potential project backers, with limited and uncertain information of these factors.

69 Much of this uncertainty stems from unknown landowner participation. At the same time,

70 landowners must decide whether or not to participate in the project without knowing the

71 turbine locations and the potential impacts. Both stakeholders, developers and landowners,

72 face high levels of risk.

73 It is customary for developers to offer all landowners in a project the same

74 compensation structure. However, they make no profit guarantees to landowners. The

75 contract offers a certain dollar compensation per MW per year if developers install

76 turbines, but they may not install any. In this situation, the land is still under contract with

77 the developer, so landowners cannot work with another developer or install their own

78 turbines. Thus, landowners sign away the rights to their land without knowing if they will

79 receive compensation from wind energy produced. This is a large risk. Developers offer

80 particular riders for other disturbances, such as dollar per decibel-level-range noise

81 disturbance and dollar per unit of road built, but do not specify the level of noise or amount

82 of road construction. The agreement also does not specify turbine location on land parcels,

83 or number of turbines. Therefore, it is difficult for landowners to assess compensation

84 packages. Clearly, both stakeholders would benefit from increased information in early-

85 stage farm development. This could decrease both development time, via more-transparent

86 negotiations, and COE, via addressing uncertainty in planning.

$87 \quad$ This paper uses an optimization-under-uncertainty framework developed

88 previously by the authors (Chen, 2013; Chen and MacDonald, 2015, 2013), to specifically

89 address two major soft-cost challenges: (a) determine land lease terms for all participating 
90 landowners and (b) determine noise disturbance compensation. The robust design

91 optimization problem has two objectives for the farm's COE: minimize the normalized mean

92 value and standard deviation. The authors use probability theory to model the uncertain

93 parameters, Latin Hypercube Sampling to propagate the uncertainty throughout the COE

94 system model, and compromise programming to solve the multi-objective optimization

95 problem. The system model provided in this paper can help developers identify plots of

96 land that are worth the extra investment, and provide a robust wind farm design that is not

97 only profitable but also has minimal noise disturbance for landowners. It can also give

98 landowners an idea of where turbines are likely to be placed on their land, and the likely

99 auditory impacts.

\section{Methods}

\section{$101 \quad 2.1 \quad$ Test case with real farmland and house locations}

In previous related publications, we have used simulated land plots. However, to

103 explore real noise issues and lease concerns, it was necessary to use real land with real

104 home locations, shown in Figure 1, which also shows potential turbine locations, discussed

105 later in Section 2.5.2. A portion of the Story County Wind Farm (Wikipedia, 2013) in central

106 Iowa was selected as a realistic test case. The farm is operated by NextEra Energy (Takle

107 and Lundquist, 2011). The land parcels within the 2-by-2 mile test area are owned by 22

108 landowners, and most own multiple land parcels. Figure 1 shows the test area; black lines

109 outline the individual land parcels, each parcel is labeled by landowner id (1 to 22),

110 followed by a parcel counter. For example, 9-1 indicates the first parcel owned by

111 landowner 9, 9-2 the second parcel owned by landowner 9, etc. Note that all parcels owned 
112 by the same landowner will have same acceptance profiles for compensation offers and

113 noise disturbance. Note also that not all parcels owned by the same landowner are adjacent

114 to each other, for example see the parcels of landowners 13 and 14.

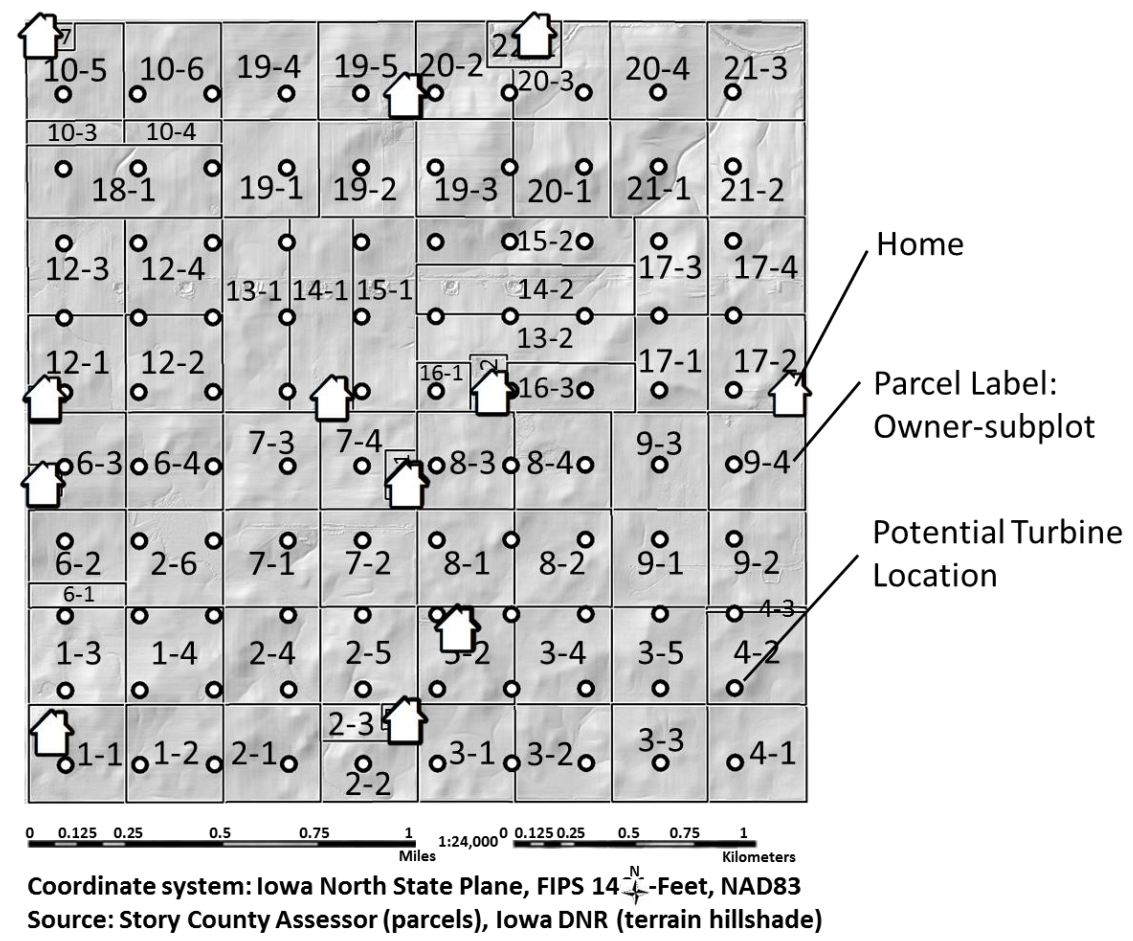

115

116 Figure 1 Test area with parcels labels, home locations, and potential locations of turbines.

117 Note, in Figure 1, the house in the top-right area: it is surrounded by land owned by

118 someone else. Such an intricacy would not be imagined in a hypothetic layout-scenario, but

119 is a reality when land is bought, sold, and passed down through inheritances. There are

120 also several cases where parcels with the same owner are not adjacent, i.e. they are

121 surrounded by non-owned parcels, as shown in Figure 1. The complexity of the spatial

122 arrangement of parcels and their ownership is a complicating, yet important factor in

123 capturing the complexities of modeling real world conditions. This is especially important

124 when adding a noise model, as noise preferences will be discontinuously (or discretely)

125 identical for some non-adjacent plots of land. 
A Geographic Information System (GIS) was used to convert public land information

127 obtained from the Iowa Story County Assessor's office into the geospatial data required to

128 run the model. ArcGIS 10 Desktop (ArcMap) was used to perform a spatial selection of

129 those parcel boundary polygons within the test area from the much larger Story county

130 data set. Coordinates were converted from the feet-based Iowa State plane system used by

131 the county, into a local, UTM (meter) based system as required by the modeling software.

132 The GIS was also used to set up the $10 \times 10$ and $24 \times 24$ patterns of potential turbine

133 locations. Satellite imagery (Digital Globe) was used to visually identify and digitize the

134 coordinates of the main house within each homestead (which is assumed to be the location

135 where owners live and experience the noise levels modeled). Extracting and anonymizing

136 the names of the parcel owners into a number system while still retaining the spatial

137 relationships required additional custom programming with the ArcGIS Python API. Maps,

138 combining the parcels, locations of houses and of potential wind turbine locations (Figures

139 4, 6, and 8) were also designed in ArcMap. To facilitate communication within the team and

140 with other project participants, a public online map was created in ArcMap Online:

141 arcg.is/1gSC75q. This can be used by other researchers.

\section{$142 \quad 2.2$ System model overview}

143 Figure 2 represents the overview of the COE system model used in this work. Five

144 models are used to calculate the COE: a noise propagation model (introduced in detail in

145 Section 2.4.4), an enhanced cost model developed based on the Wind Turbine Design Cost

146 and Scaling Model (Fingersh et al., 2006) by NREL and the Turbine System Cost Report from

147 Lawrence Berkeley National Laboratory (Bolinger and Wise, 2011), a wind shear model

148 (Ray et al., 2006), Jensen's (1983) wake loss model, and a power model for a GE 1.5sle 
149 turbine (Archer and Jacobson, 2007). The authors' previous work (Chen, 2013; Chen and

150 MacDonald, 2015, 2013) discusses the latter four models. The NREL model includes all

151 costs associated with the construction of a wind farm, including the costs of cabling, roads,

152 and transportation, although these costs do not change based on the locations of the

153 turbines. The assumed land lease costs within the NREL model are removed and replaced

154 by the work here. The cost model here has the additional constraint of equal compensation

155 structures for all participating landowners and eliminates the unnecessary economies-of-

156 scale cost reduction coefficient, as explained later in this section.

157 The model includes four sources of uncertainty, indicated in gray in Figure 2. Wind

158 condition is modeled as aleatory uncertainty using a wind rose, shown in detail in section

159 2.5.2. Three epistemic sources of uncertainty are modeled in this paper: wind shear, same

160 as in previous work (Chen, 2013; Chen and MacDonald, 2015, 2013); landowner

161 participation, with more detail given in previous work (Chen, 2013; Chen and MacDonald,

1622015,2013 ) and Section 2.4.3; and monetary compensation required for a given noise

163 disturbance, as represented by a Willingness-to-Accept-Noise utility model, explained

164 below. There are multiple sources of uncertainty within the noise propagation model, but

165 they are self-contained and not detailed here. 


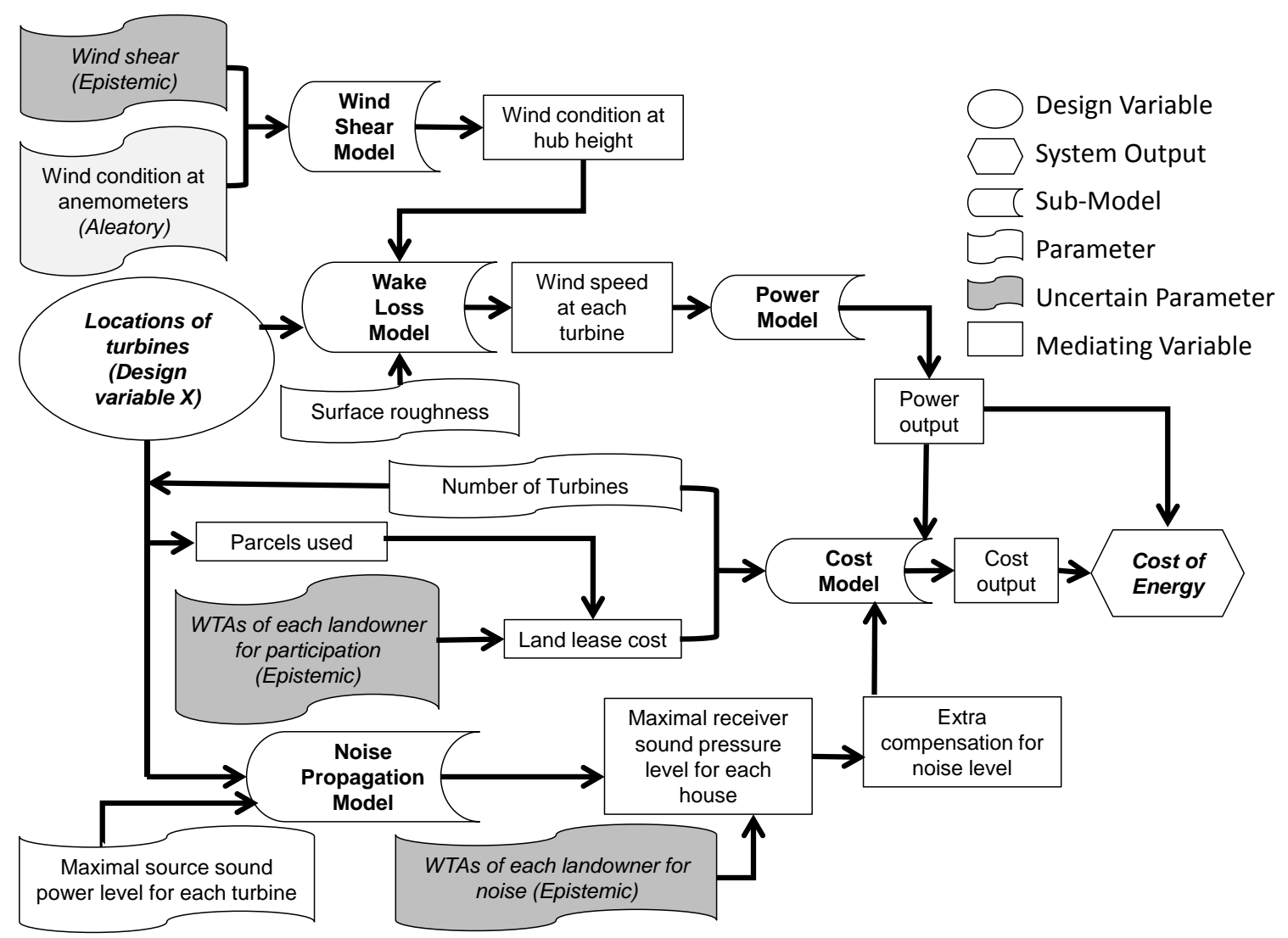

167 Figure 2 Overview of the COE model with a noise model.

168 While this is useful for the conclusions drawn in previous work, it is not realistic

169 enough for a detailed soft costs model. In reality, instead of individual negotiations, which

170 would increase the project timeline and cost, developers prefer to offer all landowners the

171 same compensation structure, namely a certain dollar per MWh with riders to cover

172 additional damage. Landowners with good wind resource but more expensive

173 compensation demands may increase compensation for all, as developers work to ensure

174 their participation. However, there is a breaking point at which even wind-wealthy

175 landowners are too expensive for the overall cost of the farm. To realistically model this

176 behavior, the model uses an equality constraint of compensation per MWh per year for all

177 landowners that participate. For each Latin Hypercube draw of $W T A_{P}$, the highest $W T A_{P}$

178 among all participating landowners determines the final, shared compensation structure 
179 offered to each. The associated costs and wind resource benefits are captured in the

180 calculated COE, ensuring that only optimally cost-effective landowners are included in the

181 final design.

\section{$182 \quad 2.3 \quad$ Economies-of-scale term determined unnecessary}

183 Another improvement of the model in this paper is the elimination of the economies-

184 of-scale turbine cost reduction coefficient. This coefficient is included in many layout

185 optimization studies (DuPont and Cagan, 2012; Grady et al., 2005; Marmidis, et al., 2008;

186 Mosetti et al., 1994), but underestimates costs. The optimal COE in the authors' previous

187 work (Chen, 2013; Chen and MacDonald, 2015, 2013) ranged from USD 42 - 48 per MWh,

188 about 10 USD lower than the real industry data. To investigate the impact of the cost

189 reduction coefficient on optimal COE, the authors conducted an optimization analysis for a

190 portion of the Story County Wind Farm (Wikipedia, 2013), varying the number of turbines

191 and the inclusion of the cost reduction coefficient, as shown in Figure 3. The line indicates

192 COE without the term, and the "X"s mark two examples of the COE with the term. The

193 authors conducted phone interviews with developers with farms in the area to establish

194 COEs, reported as ranging from USD 51-57 per MWh, and shown as a grey area in Figure 3.

195 There is no published reference for these numbers, they were collected via phone interview

196 specifically for this investigation. COEs are difficult to secure on-the-record from

197 developers, as they are competitive information. The result shows optimal COEs are closer

198 to the real industry data without the cost reduction term. In addition, when the number of

199 turbines increases, the advantage of removing cost reduction is more obvious. Therefore,

200 the authors removed the cost reduction formulation in the system model proposed in this

201 paper. 


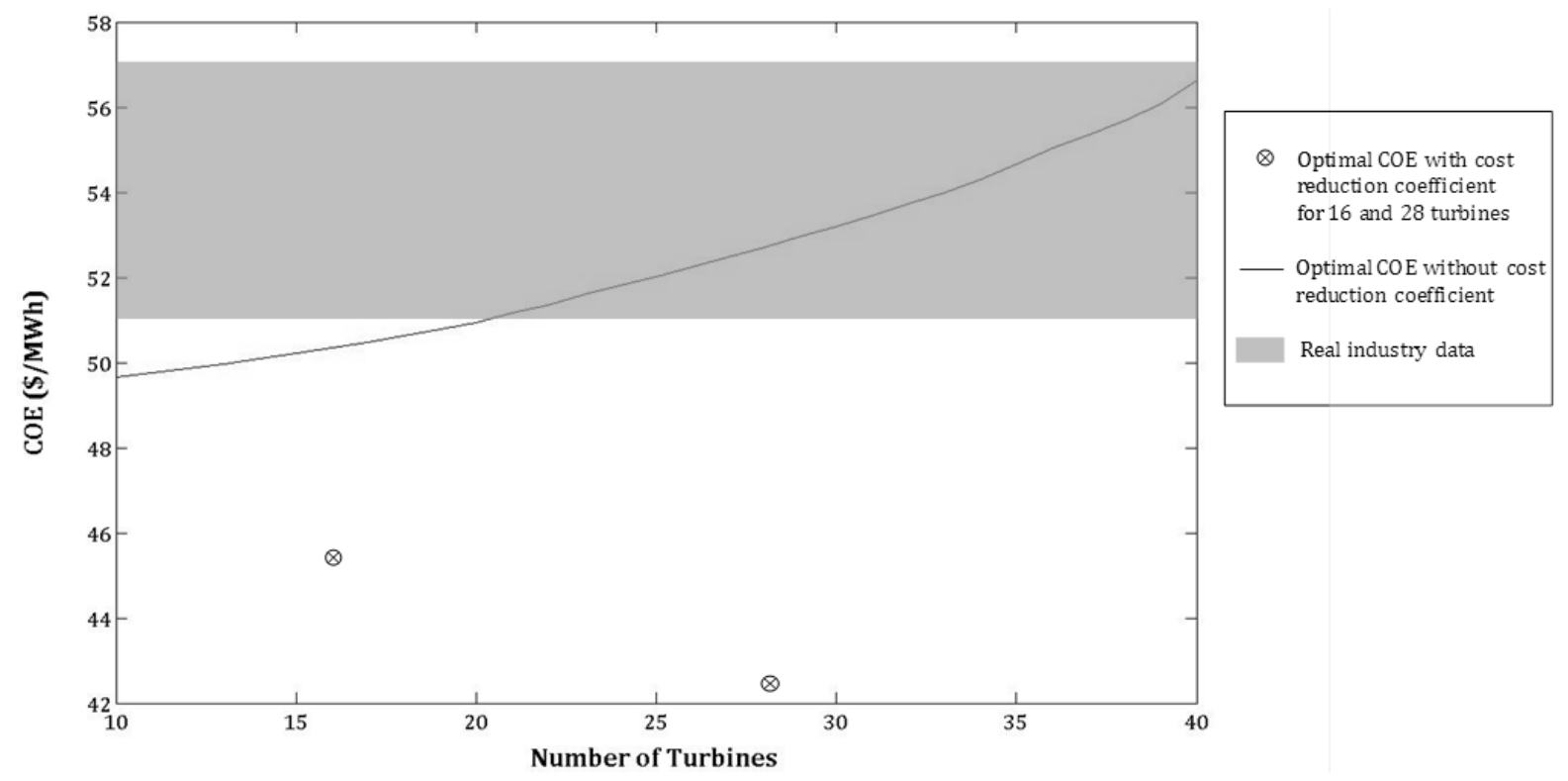

Figure 3 Relationship between the optimal COE and the number of turbines.

\section{$204 \quad 2.4 \quad$ Probabilistically modeling acceptance of noise}

When placing wind turbines near residential locations, noise impact becomes a

206 primary concern for landowners. The noise at a residential home depends on the distance

207 between the home and the surrounding turbines. A qualitative analysis conducted by Groth

208 and Vogt (2014) shows noise disturbance is one of the most commonly-stated negative

209 perceptions of wind energy development. People do not like to hear wind turbines, and

210 different people have different perceptions of it (Pedersen and Waye, 2007). Developers

211 receive complaints and lawsuits about excessive noise and its associated adverse health

212 impacts (Ambrose and Rand, 2013). For example, an Oregon landowner claimed he was

213 suffering "emotional distress, deteriorating physical and emotional health, dizziness,

214 inability to sleep, drowsiness, fatigue, headaches, difficulty thinking, irritation and lethargy"

215 due to the wind turbine noise (The Associated Press, 2013) and recently filed a related $\$ 5$

216 million lawsuit. In practice, if the noise disturbance is above a certain decibel (dB) level,

217 homeowners receive an annual compensation amount of up to $\$ 1500$ in total from 
218 developers (Mosman, 2015; Muschell, 2015). Landowners argue for safer guidelines in the

219 siting of wind turbines, as they are uncertain of the associated health risks of noise

220 disturbance (Songsore and Buzzelli, 2014).

221 If developers can guarantee the noise below a certain limit or give landowners an

222 idea of the likely auditory impact, the landowners are more likely to accept the contract.

223 Therefore, it is important to carefully model noise impact in the wind farm layout

224 optimization problem. Current wind farm layout optimization research sets noise

225 disturbance as a constraint or an objective function (Fagerfjäll, 2010; Kwong et al., 2012).

226 No existing research models monetary compensation for noise disturbance. This section

227 addresses this limitation by modeling the landowners' acceptance of noise probabilistically,

228 in combination with a constraint on maximum noise disturbance. The model is built from

229 existing research. Sections 2.4 .1 and 0 detail documentation on community reactions to

230 noise that we used to create landowner acceptance profiles. The full Willingness-to-Accept-

231 Noise model is developed in Section 2.4.3, while Section 2.4.4 provides the Noise

232 Propagation Model used in this paper.

\section{$233 \quad$ 2.4.1 Community reaction to different noise levels}

Ambrose and Rand (2013) summarized a variety of studies on the community

235 reaction to different noise levels. The results of these studies were plotted in a single chart

236 to identify noise level ranges for different community reactions, as show in Table 1 . The

237 chart indicates that people will not react adversely to a noise level below $29 \mathrm{~dB}$, but will

238 strongly oppose a noise level above $43 \mathrm{~dB}$ (about as loud as a refrigerator). Therefore, our

239 optimization formulation sets $43 \mathrm{~dB}$ as a hard constraint, i.e. the program guarantees that 
240 noise levels for all residential locations are less than $43 \mathrm{~dB}$. The model proposes: (1) if the

241 noise level is below $29 \mathrm{~dB}$, landowners will not receive any compensation; and (2) if the

242 noise level is between $29 \mathrm{~dB}$ and $43 \mathrm{~dB}$, landowners will receive compensation of up to

$243 \$ 1500$ per year-a typical amount offered by developers as compensation for noise

244 disturbance (Mosman, 2015; Muschell, 2015). Note again that solution will not include

245 noise levels above $43 \mathrm{~dB}$.

246

247 Table 1 Community Reaction for Different Noise Levels (Ambrose and Rand, 2013)

\begin{tabular}{|l|l|}
\hline Community Reaction & Noise Level $(\mathrm{dB})$ \\
\hline No Reaction & {$[0,29]$} \\
\hline Sporadic Complaints & $(29,33.5]$ \\
\hline Widespread Complaints & $(33.5,43]$ \\
\hline Strong Appeals to Stop Noise & $(43,49.5]$ \\
\hline Vigorous Community Action & $(49.5,+\infty]$ \\
\hline
\end{tabular}

\subsubsection{Landowner noise perception types}

To be able to model uncertainty, landowners are divided into three theoretically

250 possible types depending on their perception of the $43 \mathrm{~dB}$ turbine noise: (1) Type-1

251 landowners: do not notice the turbine noise of $43 \mathrm{~dB}$ and thus are not annoyed (10\%); (2)

252 Type-2 landowners: notice the turbine noise of $43 \mathrm{~dB}$, but do not feel annoyed (75\%); and

253 (3) Type-3 landowners: notice the turbine noise of $43 \mathrm{~dB}$ and do feel annoyed (15\%). The

254 model's representation of perception of noise at levels lower than $43 \mathrm{~dB}$ is explained in

255 Section 2.4.3. Note that the landowner types for noise perception are distinct from the

256 landowner land lease acceptance profiles, as discussed in the authors' previous work (Chen,

257 2013; Chen and MacDonald, 2015, 2013) and later in Section 2.4.3. Each landowner will

258 have a different profile for noise and lease acceptance. 
260 Pedersen and Waye (2007), which evaluated the perception and annoyance of wind turbine

261 noise among people living near the turbines. 754 subjects completed a postal questionnaire

262 regarding living conditions, including response to wind turbine noise. The outdoor noise

263 level for each respondent was calculated separately. Pedersen and Waye discovered that

264 when turbine noise is around $40 \mathrm{~dB}, 90 \%$ of respondents can notice the noise and $15 \%$ of

265 respondents feel annoyed. Therefore, $75 \%$ of respondents can notice the noise but do not

266 feel annoyed. This result is in line with Ambrose and R. Rand's study (2013), which asserts

267 that there are only complaints, not strong appeals, when the turbine noise is less than 43

$268 \mathrm{~dB}$. As most of the landowners are not annoyed by turbine noise around $40 \mathrm{~dB}$, they do not

269 make strong appeals to stop the noise. When the turbine noise is above $43 \mathrm{~dB}$, more

270 landowners feel annoyed. Community action might be initiated at this time. More

271 landowners get together to discuss the adverse impacts of turbine noise, which could

272 influence the landowners who do not feel annoyed, which results in wider appeals to 273 reduce the noise.

\section{$274 \quad$ 2.4.3 Willingness-to-Accept-Noise utility model}

275 In order for the landowners to be willing to accept noise compensation, the utility of

276 hearing noise plus the associated compensation must be greater than or equal to the utility

277 of not hearing noise and not receiving compensation. We define $W T A_{n, 43}$ as the minimum

278 annual payment that a landowner is willing to accept to compensate for the noise level of $27943 \mathrm{~dB}:$ 


$$
U\left(m_{0}+W T A_{n, 43}, 1\right) \geq U\left(m_{0}, 0\right)
$$

280 where $U$ is a landowner's utility function, $m_{0}$ is the landowner's initial wealth, $W T A_{n, 43}$ is

281 the landowner's minimum WTA dollar amount for a $43 \mathrm{~dB}$ noise, “1" represents the

282 presence of a $43 \mathrm{~dB}$ turbine noise at the landowner's house, and " 0 " represents the absence 283 of turbine noise at the landowner's house.

284 In this paper, $W T A_{n, 43}$ is modeled as an epistemic uncertainty. The reasonable range

285 of $W T A_{n, 43}$ is set to be between $\$ 0$ and $\$ 1500$ per year, which is the typical compensation

286 range offered by developers (Mosman, 2015; Muschell, 2015). Landowners are classified

287 into three types, each with their own uncertain $W T A_{n, 43}$, as shown in Table 2. (1) Type-1

288 landowners, as discussed above, cannot notice the turbine noise of $43 \mathrm{~dB}$. Therefore, the

$289 W T A_{n, 43}$ per year is most likely to be between $\$ 0$ and $\$ 500$ (probability = 0.7) and between

$290 \$ 500$ and $\$ 1000$ (probability = 0.3); (2) Type-2 landowners can notice the turbine noise of

$29143 \mathrm{~dB}$, but do not feel annoyed. Therefore, the $W T A_{n, 43}$ per year is equally likely to be

292 between $\$ 0$ and $\$ 500$ (probability $=0.5$ ) and between $\$ 500$ and $\$ 1000$ (probability $=0.5$ );

293 (3) Type-3 landowners feel annoyed at turbine noise of $43 \mathrm{~dB}$. Therefore, the $W T A_{n, 43}$ per

294 year is most likely to be between $\$ 1000$ and $\$ 1500$ (probability $=0.7$ ) and $\$ 500$ and $\$ 1000$

295 (probability $=0.3$ ). These probabilities and other characteristics of the landowner profiles

296 are determined by the authors from literature, but in practice can be replaced with any

297 numbers that developers or researchers see fit.

298

299 
300 Table 2 Intervals and probabilities, assumed for the $W T A_{n, 43}$.

\begin{tabular}{|l|l|l|l|}
\hline \multicolumn{4}{|l|}{$W_{n, 43}$ for Type-1 Landowners $(\$ / y r)$} \\
\hline Intervals & {$[0,500)$} & {$[500,1000)$} & {$[1000,1500]$} \\
\hline Probabilities & 0.7 & 0.3 & 0 \\
\hline$W T A_{n, 43}$ for Type-2 Landowners $(\$ / y r)$ \\
\hline Intervals & {$[0,500)$} & {$[500,1000)$} & {$[1000,1500]$} \\
\hline Probabilities & 0.5 & 0.5 & 0 \\
\hline WTA & for Type-3 Landowners $(\$ / y r)$ \\
\hline Intervals & {$[0,500)$} & {$[500,1000)$} & {$[1000,1500]$} \\
\hline Probabilities & 0 & 0.3 & 0.7 \\
\hline
\end{tabular}

301 Given the $W T A_{n, 43}$ amount (\$/yr) of a landowner, the authors assume that the

302 landowner's minimum WTA amount for a noise level of $L_{A T}$ follows a linear relationship:

$$
W T A_{n}\left(L_{A T}\right)=\left\{\begin{array}{cl}
0 & L_{A T} \leq 29 \mathrm{~dB} \\
\frac{\left(L_{A T}-29\right) \times W T A_{n, 43}}{43-29} & 29 \mathrm{~dB}<L_{A T}<43 \mathrm{~dB} \\
W T A_{n, 43} & L_{A T}=43 \mathrm{~dB} \\
\inf & L_{A T}>43 \mathrm{~dB} .
\end{array} .\right.
$$

303 Where $W T A_{n}\left(L_{A T}\right)$ is the landowner's minimum WTA amount in $\$ / y r$ for a noise

304 level of $L_{A T} ; L_{A T}$ is real receiver noise level in $\mathrm{dB}$ at the landowner's house, calculated

305 using the Noise Propagation Model described in Section 2.4.4; $W T A_{n, 43}$ is the given WTA

306 amount $(\$ / \mathrm{yr})$ of the landowner for a $43 \mathrm{~dB}$ noise.

307 As discussed above, when the noise level is below $29 \mathrm{~dB}$, landowners will have no

308 reaction according to Ambrose and Rand (2013). Therefore, $W T A_{n}\left(L_{A T}\right)$ is set to be 0 when

$309 L_{A T}$ is below $29 \mathrm{~dB}$, indicating landowners are willing to accept a noise level below $29 \mathrm{~dB}$ 
310 without compensation. However, when the noise level is above $43 \mathrm{~dB}$, landowners will have

311 strong appeals to stop noise (Ambrose and Rand, 2013). Therefore, $W T A_{n}\left(L_{A T}\right)$ is set to be

312 infinite when $L_{A T}$ is above $43 \mathrm{~dB}$, indicating landowners are not willing to accept a noise

313 level above $43 \mathrm{~dB}$ no matter how much compensation they receive from developers.

314 Similar to the equal land lease compensation constraint, the model has an equal

315 compensation constraint for noise disturbance. After the optimization algorithm draws the

316 noise acceptance profiles for all landowners, it sets the $W T A_{n}$ for a $43 \mathrm{~dB}$ noise for all the

317 landowners to the value associated with the least-accepting (most costly) landowner that

318 has been chosen to participate in the iteration's design layout. For all landowners, the

319 algorithm replaces the $W T A_{n, 43}$ in Equation (2) with this most-costly WTA, and calculates

320 the final noise compensation for each landowner based on the noise heard at their home.

\section{$321 \quad 2.4 .4 \quad$ Noise propagation model}

322 The noise propagation model used here is based on ISO 9613-2 (1996):

$$
L_{A T}=10 \lg \left\{\sum_{i=1}^{n}\left[\sum_{j=1}^{8} 10^{0.1\left[L_{f T}(i j)+A_{f}(j)\right]}\right]\right\},
$$

323 where $L_{A T}$ is the A-weighted downwind sound power level at a receiver location

324 (landowner's house), $n$ is the number of noise sources (number of turbines), $i$ is an index

325 representing the noise sources, $j$ is an index representing the eight standard octave-band

326 midband frequencies, $A_{f}(j)$ is the standard A-weighting (IEC 651 or IEC 61672), and

$327 L_{f T}(i j)$ is sound pressure level at a receiver location for noise source $i$ and octave-band $j$ : 


$$
L_{f T}(i j)=L_{W}+D_{C}+A
$$

328 Here $L_{W}$ represents the octave-band sound power level for the noise source (turbine), $D_{C}$

329 is the directivity correction, which is neglected in this work, and the octave-band

330 attenuation $A$ is defined as the sum:

$$
A=A_{d i v}+A_{a t m}+A_{g r}+A_{b a r}+A_{m i s c},
$$

331 where $A_{d i v}$ is the attenuation due to geometrical divergence (spreading of sound waves in

332 3D space), defined as

$$
A_{d i v}=\left[20 \lg \left(d / d_{0}\right)+11\right] \mathrm{dB},
$$

333 where $d$ is the distance from the source to receiver and $d_{0}$ is the reference distance $(1 \mathrm{~m})$.

The attenuation due to atmospheric absorption $\left(A_{\text {atm }}\right)$ is calculated as:

$$
A_{\text {atm }}=a_{c} d / 1000
$$

335 where $a_{c}$ is the atmospheric attenuation coefficient. The yearly average temperature and

336 relative humidity for Ames in 2011 are $9.2 \mathrm{deg} \mathrm{C}$ and $77 \%$ according to the real data

337 obtained from the Iowa Environmental Mesonet (2013b). Therefore, the value of $a_{c}$ for a

338 temperature of $10{ }^{\circ} \mathrm{C}$ and relative humidity of $70 \%$ is used for all computations in this 339 research.

340 The attenuation due to the ground effect $\left(A_{g r}\right)$ is defined as

$$
A_{g r}=A_{s}+A_{r}+A_{m}
$$

341 The detailed method for calculating attenuations with regard to source region $\left(A_{s}\right)$, receiver

342 region $\left(A_{r}\right)$, and middle region ( $\left.A_{m}\right)$ is described in ISO 9613-2 (1996). The authors 
343 assume that the ground is porous for source region, middle region, and receiver region

$344(\mathrm{G}=1)$. The model assumes that entire noise radiation from a turbine can be approximated

345 to be emanating from a single point located at the turbine hub height. The turbine hub

346 height is taken to be $80 \mathrm{~m}$, and the receiver height to be $2 \mathrm{~m}$.

347 The model ignores attenuation due to screening obstacles $\left(A_{b a r}\right)$ and from other

348 miscellaneous barriers $\left(A_{\text {misc }}\right)$; a reasonable approach for wind farms in Iowa, which are

349 typically installed in farming land with very few buildings or swaths of trees.

$350 \quad 2.5$ Problem Formulation

351 2.5.1 Distribution of landowner types for lease acceptance and noise perception

352 In the authors' previous work (Chen, 2013; Chen and MacDonald, 2013), the

353 authors summarized wind project easement and lease data from published sources

354 (Windustry, 2009), and found out the compensation per MW installed per year for

355 landowners typically ranged from $\$ 1000$ to $\$ 5000$ with a mean value of $\$ 2757$. To model

356 the uncertainty associated with land lease compensation, the authors took into account an

357 uncertain $W T A_{P}$ in previous work (Chen, 2013; Chen and MacDonald, 2015, 2013). The

358 range of $W T A_{P}$ was assumed to be from $\$ 1000$ to $\$ 50000$ per MW installed per year. The

359 upper limit of $W T A_{P}(\$ 50000)$ approximates the entire property value, assuming there are

360 multiple turbines on the land. The higher the $W T A_{P}$, the more reluctant the landowner, i.e.

361 the reluctant landowner will only participate in the project when the compensation is very

362 high. In extreme situation, the most reluctant landowner will only participate when the

363 compensation is equal to the value of his/her property. 
365 Table 3 Intervals and probabilities, assumed for the $W T A_{P}$.

\begin{tabular}{|l|l|l|l|}
\hline$W T A_{P}$ for Type-A Landowners $(\$ /$ yr per MW installed) \\
\hline Intervals & {$[1000,2500)$} & {$[2500,5000)$} & {$[5000,50000]$} \\
\hline Probabilities & 0.5 & 0.5 & 0 \\
\hline$W T A_{P}$ for Type-B Landowners $(\$ /$ yr per MW installed) \\
\hline Intervals & {$[1000,2500)$} & {$[2500,5000)$} & {$[5000,50000]$} \\
\hline Probabilities & 0.3 & 0.7 & 0 \\
\hline$W T A_{P}$ for Type-C Landowners $(\$ /$ yr per MW installed) \\
\hline Intervals & {$[1000,2500)$} & {$[2500,5000)$} & {$[5000,50000]$} \\
\hline Probabilities & 0 & 0.5 & 0.5 \\
\hline$W T A_{P}$ for Type-D Landowners $(\$ /$ yr per MW installed $)$ \\
\hline Intervals & {$[1000,2500)$} & {$[2500,5000)$} & {$[5000,50000]$} \\
\hline Probabilities & 0 & 0.3 & 0.7 \\
\hline
\end{tabular}

366 Table 4 Landowner type for lease acceptance, assumed for 22 landowners.

\begin{tabular}{|l|l|}
\hline Landowner type for lease acceptance & Landowner ID \\
\hline Type-A & Landowners 4, 5, 12,15, 18, and 19 \\
\hline Type-B & Landowners 1, 3, 6, 9, 11, 14, 16, and 22 \\
\hline Type-C & Landowners 2, 7, 13, 17, and 21 \\
\hline Type-D & Landowners 8, 10, and 20 \\
\hline
\end{tabular}

367 The range of $W T A_{P}$ was split into three intervals: (1) interval [1000, 2500)

368 indicates a low $W T A_{P} ;(2)$ interval $[2500,5000)$ indicates a moderate $W T A_{P}$; and (3)

369 interval $[5000,50000)$ indicates a high $W T A_{P}$. Four types of landowners are modeled with

370 different land lease acceptance profiles, each with their own uncertain $W T A_{P}$. Table 3

371 provides the assumed $W T A_{P}$ for each landowner type: (1) Type-A landowners will accept

372 low compensation. The $W T A_{P}$ is equally likely to be between $\$ 1000$ and $\$ 2500$

373 (probability $=0.5$ ) and between $\$ 2500$ and $\$ 5000$ (probability $=0.5$ ); (2) Type-B

374 landowners will accept moderate compensation. The $W T A_{P}$ is more likely to be between

$375 \$ 2500$ and $\$ 5000$ (probability = 0.7); (3) Type-C landowners will accept high or moderate

376 compensation. The $W T A_{P}$ is equally likely to be between $\$ 2500$ and $\$ 5000$ (probability =

3770.5 ) and between $\$ 5000$ and $\$ 50000$ (probability $=0.5$ ); and (4) Type-D landowners will 
378 only accept high compensation. The $W T A_{P}$ is more likely to be between $\$ 5000$ and $\$ 50000$ 379 (probability $=0.7$ ). Here, the probabilities hypothetical. In practice, developers will 380 estimate probabilities and assign types based on interactions with landowners. All 381 landowners were randomly assigned a type, as shown in Table 4 and Figure 4, as in the 382 authors' previous work (Chen, 2013; Chen and MacDonald, 2015, 2013).

$383 \quad$ Figure 4 shows the location of the twelve houses, owned by 9 landowners, used as 384 the noise receivers in this paper. In Figure 4, the central location of each house is marked 385 with a small house symbol. Homeowners/landowners are modeled with three noise 386 perception profiles, i.e. uncertain $W T A_{n, 43}$ values range from $\$ 0$ to $\$ 1500$ per year, shown 387 previously in Table 2. Based on the study conducted by Pedersen and Waye (2007), as 388 discussed in Section 2.4.2, the percentages for Type-1, Type-2, and Type-3 landowners are $38910 \%, 75 \%$, and $15 \%$ respectively. Therefore, the formulation assumes one type-1

390 landowner, seven type-2 landowners, and one type-3 landowner. These types are assigned 391 randomly, and the houses are shaded by type in Figure 4. 


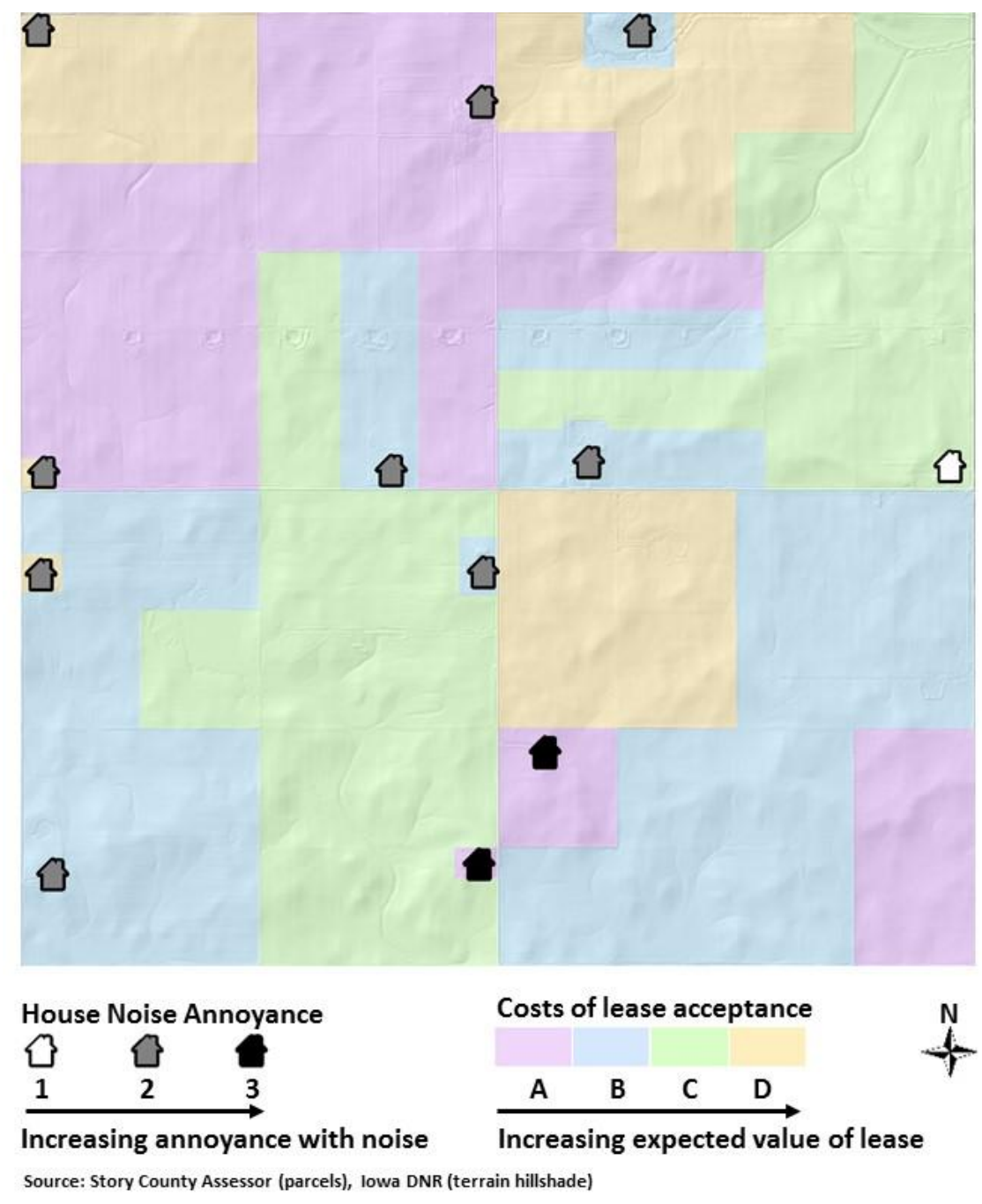

393 Figure 4 Three noise perception types and four lease acceptance types are assigned

394 randomly in the test area.

\subsubsection{Wind Condition and Potential Turbine Areas}

The system model presented in this section allows for 100 potential locations for

397 turbines, as indicated by the white circles in Figure 1. The distance between any two

398 potential locations is set to be more than four rotor diameters to reduce wake interactions,

399 a typical setting in wind farm layout optimization literature (Ozturk and Norman, 2004; 
400 Kusiak and Song, 2010). The appendix modifies the formulation with more potential

401 locations to investigate a higher-resolution solution space.

402 Wind condition of the test area. The authors used the actual one-year wind data of 4032011 from the Iowa Environmental Mesonet (2013a) website to model the wind condition

404 of the test area. Figure 5 shows the wind rose plot downloaded from the Iowa

405 Environmental Mesonet (2013b). 10-meter-high anemometers were used to collect the

406 data, which range from 3 knots to 38 knots with a mean value of 9 knots.

407

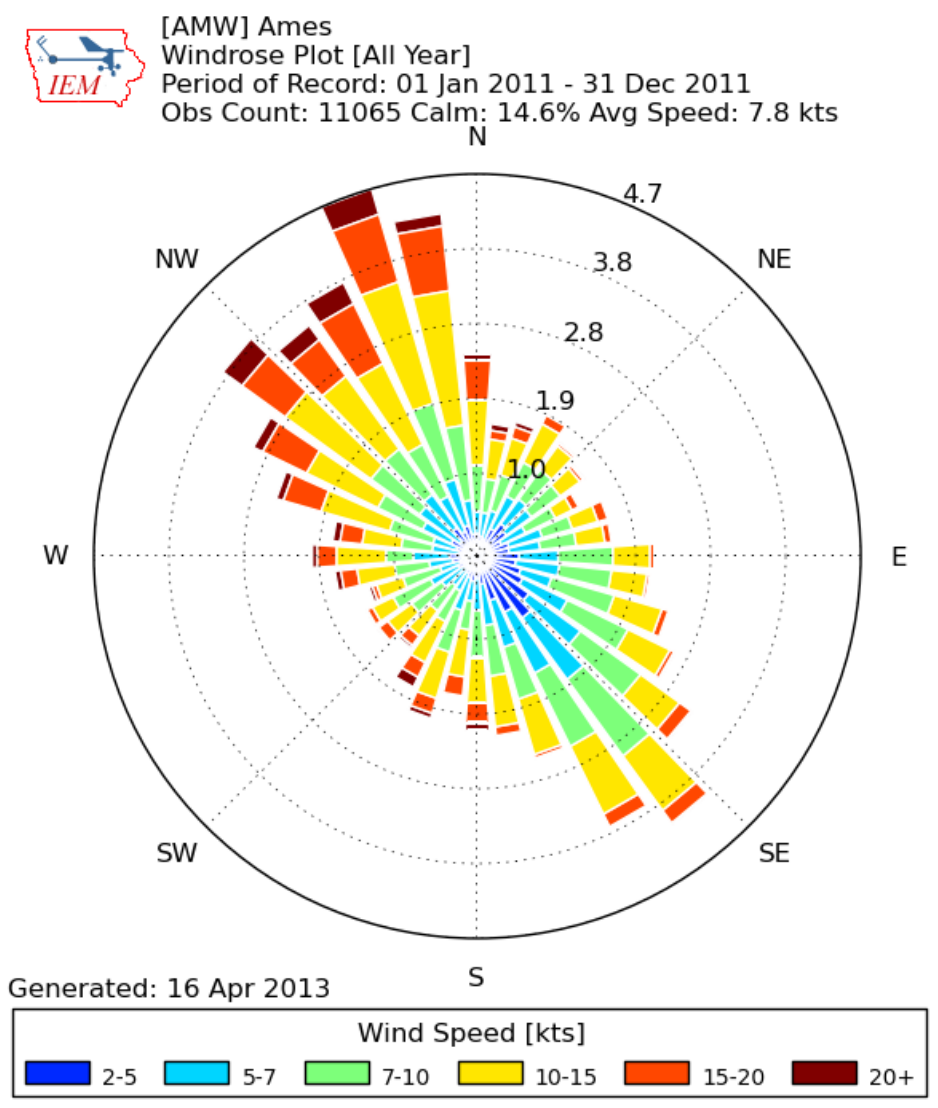

409 Figure 5 Wind rose generated from the Iowa Environmental Mesonet website (Iowa

410 Environmental Mesonet, 2013b). 
412 complicated wind models are available in the literature. For example, Erdem and Shi (2011)

413 proposed and compared seven bivariate wind distribution models. Zhang et al. (2011) used

414 Kernel Density Estimation to construct a multivariate and multimodal wind model.

415 Researchers, such as Morgan et al. (2011) and Carta et al. (2009) conducted thorough

416 reviews on a variety of wind models, and found out Weibull distribution was able to fit most

417 wind data well. The authors also proved in previous work (Chen, 2013; Chen and

418 MacDonald, 2015, 2013) that Weibull distribution can fit the wind data of Iowa well.

419 Equation(9) provides the Probability Density Function (PDF) of Weibull Distribution

420 (Lackner and Elkinton, 2007), which defines wind speed $v$ as a function depending on the

421 shape factor $k$ and the scale factor $\lambda$. More details of this wind model can be found in the 422 authors' previous work (Chen, 2013; Chen and MacDonald, 2015, 2013).

$$
P D F(v)=\frac{k}{\lambda}\left(\frac{v}{\lambda}\right)^{k-1} e^{-\left(\frac{v}{\lambda}\right)^{k}}
$$

\section{$423 \quad 2.5 .3 \quad$ Objective function}

424 The objective for the deterministic system model is to minimize the COE given the

425 environmental parameters $P$ and a fixed number of turbines (16 turbines for the selected 426 piece of land), defined as:

$427 \quad$ Minimize:

428 subject to:

$$
C O E(X, P)=\frac{C(X, P)}{A E P_{t o t}(X, P)}
$$

$$
h(X)=N(X)=16
$$


429 where $\operatorname{COE}(X, P)$ is the levelized cost of energy of the wind farm in $\$ / \mathrm{MWh}$, as detailed in

430 the authors' previous work (Chen, 2013; Chen and MacDonald, 2015, 2014, 2013), $C(X, P)$

431 is the levelized cost per year of a wind farm in dollars, $A E P_{t o t}(X, P)$ is the farm's total

432 annual energy in MWh, $h(X)$ is the equality constraint, and $N(X)$ is the total number of

433 turbines in the farm. $X$ is a 100-bit binary string design variable representing the potential

434 turbine locations shown in Figure 1. The equality constraint $h(X)$ indicates that the total

435 number of turbines selected by the optimization program will be fixed at 16 . This number is

436 selected based on the actual number of turbines within the test area. In practice, it is

437 straightforward to modify this number to meet the developers' needs.

\section{$438 \quad 3 \quad$ Results and discussion}

\section{$439 \quad 3.1 \quad$ Results}

440 GAlib, a library of genetic algorithms (GAs) developed by Wall (1999), was used to

441 solve the optimization problem in $\mathrm{C}++$. GA is a widely-used heuristic probabilistic search

442 algorithm (Grady et al., 2005), which does not require a differentiable objective function

443 and are less likely to get trapped in a local optimum (Houck et al., 1995; Davis, 1991). GAs

444 are also commonly used as a stochastic heuristic algorithm to optimize wind farm layout

445 (Sorkhabi et al., 2016).The authors decided to use GA as: (1) the design variable in this

446 work is a binary string; (2) the objective function is non-differentiable; and (3) it is likely to

447 have more than one optimal layout (multi-modal).

448 The design variable was a binary vector of the turbine locations $(=1$ with a turbine

449 placed and 0 without). This paper used a penalty function for constraint violation, similar 
450 as in previous work (Chen, 2013; Chen and MacDonald, 2015, 2014, 2013, 2012), to address

451 the equality constraint of Equation (11). The optimization program ran in three different

452 scenarios: (1) minimize the mean value of $\operatorname{COE}\left(\mu_{C O E}\right)$; (2) minimize the standard deviation

453 of $\operatorname{COE}\left(\sigma_{C O E}\right)$; and (3) compromise programming with two minimization objectives: the

454 normalized mean value of $\operatorname{COE}\left(\frac{\mu_{C O E}}{\mu_{C O E}^{*}}\right)$ and standard deviation of $\operatorname{COE}\left(\frac{\sigma_{C O E}}{\sigma_{C O E}^{*}}\right)$, where $\mu_{C O E}^{*}$

455 and $\sigma_{C O E}^{*}$ are the individually-optimized mean value and standard deviation of COE.

456 For each scenario, the program ran over ten times with 10,000 iterations each time,

457 at which point it would terminate. Each of the ten runs took four hours to complete. The GA

458 uses a multitude of initial locations of the turbines in order to aid in convergence to the

459 global optimum. The best results of these ten runs are shown in Table 5. The noise levels for

460 the houses ranged from $34 \mathrm{~dB}$ to almost $43 \mathrm{~dB}$, as shown in Figure 6.

461 Table 5 Results summarized from the optimization program for 16 turbines with 100

462 potential turbine locations.

\begin{tabular}{|c|c|c|c|}
\hline Scenario & 1 & 2 & 463 \\
\hline Objectives & $\begin{array}{l}\text { Minimize } \\
\mu_{C O E} \\
\text { Individually }\end{array}$ & $\begin{array}{l}\text { Minimize } \\
\sigma_{C O E} \\
\text { Individually }\end{array}$ & $\begin{array}{l}\text { Minimize } \\
{\left[\frac{\mu_{C O E}}{\mu_{C O E}^{*}}, \frac{\sigma_{C O E}^{464}}{\sigma_{C 4655}^{*}}\right.}\end{array}$ \\
\hline$\mu_{C O E}(\$ / \mathrm{MWh})$ & 52.44 & 52.51 & 52.44 \\
\hline$\sigma_{C O E}(\$ / \mathrm{MWh})$ & 5.08 & 5.08 & 5.08 \\
\hline $\begin{array}{l}\mu \text { Energy Output } \\
\text { (MWh/yr) }\end{array}$ & 73838 & 73707 & 73838 \\
\hline$\mu$ Cost Output (\$k/yr) & 3831 & 3829 & 3831 \\
\hline
\end{tabular}

469 As shown in Table 5, all three scenarios have very similar COEs (around 52.5

$470 \$ / M W h)$ with the same standard deviation (5.08 \$/MWh). The Pareto frontier of COE varies 
471 only by cents, thus it is not included as a figure. A similar finding is discussed in the authors'

472 previous work (Chen and MacDonald, 2015) indicating that the variance of COE is mainly

473 the result of changing the number of turbines in the problem set-up. Minimizing $\mu_{C O E}$

474 (Scenario 1) and $\mu_{C O E} \& \sigma_{C O E}$ (Scenario 3) share very similar mean energy outputs and

475 costs. This is because $\sigma_{C O E}$ does not vary when the number of turbines is fixed. Because the

476 results are similar, we only discuss further the results of minimizing $\mu_{C O E}$ and $\sigma_{C O E}$

477 (Scenario 3), as shown in Figure 6, with $\bigotimes$ representing an optimized turbine location.



479 Figure 6 Scenario 3 (minimizing $\mu_{C O E} \& \sigma_{C O E}$ ) has a COE of $52.44 \$ / \mathrm{MWh}$. 
481 level, $43 \mathrm{~dB}$, while house $\gamma$ receives the lowest. As shown in Figure 6, house $\beta$ is owned by a

482 Type-1 landowner, who does not hear the turbine noise of $43 \mathrm{~dB}$. The noise level for this

483 house is one of the highest because the associated payment to the landowner is low. On the

484 contrary, house $\alpha$ is owned by a Type-3 landowner, who will feel annoyed at turbine noise

485 of $43 \mathrm{~dB}$. To reduce compensation cost for noise disturbance, the noise level of house $\alpha$

486 should be minimized. However, house $\alpha$ is located at the boundary of the entire land plot,

487 which is favored by the optimization program to minimize wake losses (Barthelmie, 2006).

488 Therefore, the optimization program does not avoid placing turbines around house $\alpha$, as the

489 turbine location benefits outweigh the required extra compensation for noise disturbance.

490 On the other hand, house $\gamma$, which is also located at the boundary of the entire land plot,

491 receives the lowest noise level. This is because house $\gamma$ is surrounded by a Type-D

492 landowner (shaded by yellow), who has the highest remittance requirement for

493 participating in the project (see Section 2.5.1 above). If turbines are placed on the land of a

494 Type-D landowner, all the other landowners would have to receive the same high

495 remittance fees package. Therefore, to save on the overall remittance fees for participation,

496 no turbines are placed around house $\gamma$, which results in the lowest noise level of house $\gamma$.

497 Similarly, none of the three scenarios placed any turbines on the land of other type-D

498 landowners (parcels shaded by yellow), in order to keep overall remittance fees down.

\section{$499 \quad 3.2$ Implementation Discussion}

500 Implementation of the proposed model framework can initiate from a number of 501 perspectives. For researchers, large-scale developers, and governmental policy-makers, the 
502 coding and parameters are straight-forward to implement. Wind resource and GIS data are

503 readily available. The parameters in the NREL-based portions of the model will require

504 careful review, as there are a number of assumptions that will change with time, such as the

505 cost and power curves of readily-available turbines. Although the authors used C++,

506 MATLAB is another platform that can run the optimizations at a slower speed, which will be

507 manageable with total turbine counts of 20 or less. Developers that we have spoken to

508 approach land owner negotiations carefully, and have much experience gauging their

509 responsiveness from limited conversations, such as town dinners or door-to-door

510 conversations. Such interactions would be best to define the parameters related to

511 landowner acceptances of noise and risk. Note that zoning regulations and road

512 construction regulations are not included in this model. These additional constraints are

513 necessary past the initial planning stages, and can be added to the model.

514 For landowners, the best path to implementation would be to work with an

515 engineering consultant who can implement the code and collect the required data. It could

516 also be possible to create an online assessment tool-NREL already has similar tools

517 available-and it is possible that this could give landowners significantly more power in

518 negotiations.

519 In summary, a step-by-step path to implementation would be as follows: (1) Identify

520 parameters within the model and update as necessary to apply to the specific situation,

521 confirm availability of wind and GIS data; (2) Conduct discussions with landowners and

522 other stakeholders to populate the probabilistic acceptance parameters; (3) Code the

523 model, check behavior with test scenarios; (4) Optimize with a step-up/step-down count of

524 turbines, such as 14-16-18; (5) With results, try moving turbine locations slightly 
525 north/west/east/south to determine sensitivity of results to exact turbine positioning; (6)

526 Share results with all stakeholders, update model constraints as necessary.

\section{Conclusion and policy implications}

528 This paper successfully improved the real-world validity and nuanced modeling of

529 landowner concerns in WFLO. New contributions in this work included: (a) the use of real-

530 world land parcels and home locations, which lead to interesting findings on which land

531 parcels guided the cost of acquiring participation from landowners; (b) the determination

532 that the economy-of-scale cost reduction coefficient used in previous work underestimated

533 the cost of energy (and thus was not included in the optimization) and (c) the incorporation

534 of a noise model and probabilistic compensation response of landowners, derived from a

535 collection of real-world data sources. The new system model was tested with different

536 scenarios using realistic data from a 2 by 2 mile plot of an Iowa windfarm containing 22

537 landowners and 12 noise receivers (houses). Initially using 100 potential turbine locations,

538 the optimal mean COE value created by the model ranges from $\$ 52$ to $\$ 53$ per MWh (Table

539 5), which matches the observed COE industry data ( $\$ 51$ to $\$ 57$ per MWh).

$540 \quad$ Unlike the Wind Turbine Design Cost and Scaling Model developed by NREL

541 (Fingersh et al., 2006), that use a single number to represent land lease cost, the model

542 presented here predicts a realistic COE through the incorporation of landowners' decisions,

543 concerns, and probabilistic models of associated soft costs. The NREL model estimates a

544 cost of 1.08 \$/MWh for land lease costs, and our model offers a similar cost of 1.19 \$/MWh

545 for the farm with 16 turbines. This suggests that our model is a viable replacement for the

546 single-number approach from NREL. It offers flexibility in design with respect to land 
547 availability and noise concerns. It captures the important concept that if landowners find

548 the potential noise generated by the farm unacceptable, or are not adequately compensated

549 for hearing it, then the farm cannot be built as the landowners will decline to participate.

550 This important concept is not captured in NREL's approach, with its single \$/MWh value

551 and lack of noise impact valuation. The realistic COE predicted by this model could help the

552 DOE make better energy policy decisions that are inclusive of all stakeholders' concerns. In

553 general, the work demonstrates the potential impact of more research on landowner-

554 related issues and the associated soft costs in wind projects, similar to the work that has

555 been funded by the DOE's SunShot Initiative that targets reductions in solar energy soft

556 costs (Office of Energy Efficient and Renewable Energy, 2015b).

557 While the model presented here offers reasonable compensation values and

558 provides useful design suggestions to landowners and developers during early-stage farm

559 negotiations, it does have a few limitations that will require further input for it to be useful

560 in the field. In this paper, the estimations of uncertain parameters are all based on

561 assumptions rather than on measured values, for example, the dollar compensation values

562 in the landowner noise-acceptance profiles. For implementation, it would be best to

563 conduct interviews with developers and landowners to fine-tune these parameters.

564 Additionally, different types and sources of uncertainty could be added, such as those

565 associated with turbine failure. The noise propagation model used in the work (ISO 9613-2,

566 1996) is the industry standard, however it is fairly rudimentary. Higher-fidelity noise

567 models, such as CONCAWE, could be included in the future to further validate the results.

568 Similarly, a higher-fidelity wake loss model could also be used. 
The noise output and the optimal layout shown in Figure 6 indicates that the

570 importance of landowners to the outcome of the project depends on the wind resource

571 their parcels provide, their lease-acceptance profile, and their noise-acceptance profile. Of

572 these factors, lease acceptance (which has an uncertain range from $\$ 1000$ to $\$ 50000$ per

573 MW installed per year as shown in Table 3) plays a particularly important role - as can be

574 seen in Figure 6, all optimal layouts avoid placing turbines on parcels owned by the

575 landowners that demand the most compensation, type-D and type-C landowners. Noise

576 acceptance plays a less important role in determining crucial landowners, because the

577 compensation for noise annoyance has a much smaller impact on overall farm COE. For

578 example, Figure 6 shows that the noise level of house $\alpha$ is at the highest level ( $43 \mathrm{~dB})$,

579 although it is owned by a landowner with a high noise compensation request, indicating

580 that the location benefit of house $\alpha$ outweighs the required additional noise compensation.

581 The results indicate that minimizing $\mu_{C O E}$ individually provides almost identical

582 COE when compared to minimizing $\mu_{C O E}$ and $\sigma_{C O E}$ combined, as $\sigma_{C O E}$ is largely dependent

583 on the number of turbines, which is fixed in this model. This finding can be beneficial for

584 developers; if the number of turbines for a farm is predetermined, running only the

585 scenario to minimize the mean value of COE may be sufficient to obtain a robust optimal

586 farm layout. This saves considerable time and computing when planning a wind farm

587 project. Additionally, a higher-resolution solution space with 576 potential turbine

588 locations, instead of 100 locations, is investigated in the Appendix. The optimal $\mu_{C O E}$ for

589576 potential turbine locations is only $0.7 \%$ better than that for 100 potential turbine

590 locations while requiring substantially more computing resources, suggesting it may serve a 
591 better role in fine turning locations later in the project when geological concerns are 592 included.

593 The implementation of the work is straightforward and extendable beyond the case

594 study by combining existing data sources for wind, land, turbine, and cost parameters.

595 Landowner acceptance probabilistic ranges and corresponding compensation values can be 596 estimated with industry expertise and/or landowner participation. Thus, the approach

597 here, with limitations noted above, emphasizes that not only are soft costs an important and 598 deciding factor in wind-farm development, but also that these costs are not as "soft" as

599 some models suggest - it is possible to put "hard" numbers behind them, with the aid of 600 uncertainty.

\section{Acknowledgments}

602 The research reported in this manuscript was supported in-part by the Department 603 of Energy Sciences under Contract No. DEAC02- 07CH11358. The funding source had no 604 involvement in this research. The authors thank Dr. William Ross Morrow for his support in 605 this research.

606

607 NOMENCLATURE

$608 a_{c} \quad$ Atmospheric attenuation coefficient

$609 A \quad$ Octave-band attenuation

$610 A_{a t m} \quad$ Attenuation due to atmospheric absorption

$611 \quad A_{b a r} \quad$ Attenuation due to screening obstacles

$612 \quad A_{d i v} \quad$ Attenuation due to geometrical divergence 
$613 \quad A_{f}(j) \quad$ Standard A-weighting

$614 \quad A_{m} \quad$ Attenuation for the middle region

$615 A_{\text {misc }} \quad$ Attenuation from other miscellaneous effects during propagation through

$616 \quad$ foliage or buildings

$617 \quad A_{r} \quad$ Attenuation for the receiver region

$618 \quad A_{s} \quad$ Attenuation for the source region

$619 A E P_{\text {tot }}(X, P)$ Farm's total annual energy in MWh

$620 \quad C(X, P) \quad$ Levelized cost per year of a wind farm in dollars

$621 \operatorname{COE}(X, P) \quad$ Cost of Energy of the farm in \$/MWh

622 COE Cost of Energy

$623 d \quad$ Distance from the source to receiver

$624 \quad d_{0} \quad$ The reference distance $(1 \mathrm{~m})$

$625 \quad D_{C} \quad$ Directivity correction

626 DOE Department of Energy

$627 \quad h(X) \quad$ Equality constraint

$628 \quad i \quad$ An index representing the noise sources

$629 j \quad$ An index representing the eight standard octave-band midband frequencies

$630 \quad L_{A T} \quad$ A-weighted downwind sound power level at a receiver location

$631 \quad k \quad$ Shaper factor for Weibull distribution

$632 \quad L_{f T}(i j) \quad$ Sound pressure level at a receiver location for source $i$ and octave-band $j$ 
$633 \quad L_{W} \quad$ Octave-band sound power level for the noise source

$634 m_{0} \quad$ Landowner's initial wealth

$635 n \quad$ Number of noise sources (number of turbines)

$636 N(X) \quad$ Total number of turbines in the farm

$637 \quad P D F(v) \quad$ Probability density function for Weibull distribution

$638 U \quad$ Landowner's utility function

$639 W_{p} \quad$ Willingness-to-Accept for participation

$640 W T A_{n, 43} \quad$ Willingness-to-Accept for a landowner at noise level of $43 \mathrm{~dB}$

$641 X \quad$ 100-bit binary string design variable

$642 \mu_{C O E}$

Mean value of Cost of Energy

$643 \mu_{C O E}^{*}$

Optimal mean value if optimize $\mu_{C O E}$ individually

$644 \sigma_{C O E}$

Standard deviation of Cost of Energy

$645 \sigma_{C O E}^{*}$

Optimal standard deviation if optimize $\sigma_{C O E}$ individually

$646 \alpha \quad$ House label

$647 \quad \beta \quad$ House label

$648 \gamma \quad$ House label

$649 \varepsilon \quad$ Previous turbine location shown in Figure 8

$650 \quad \varepsilon^{\prime} \quad$ New turbine location shown in Figure 8

$651 \lambda \quad$ Scale factor for Weibull distribution

652 


\section{APPENDIX}

\section{Improved results with higher resolution solution space}

655

656

657

658

659

660

661

662

663

664 times longer than that for 100 potential turbine locations.

665 Table 6 Results summarized from the optimization program for 16 turbines with 576

666 potential turbine locations.

\begin{tabular}{|l|l|}
\hline Scenarios & 1 \\
\hline Objectives & Minimize $\mu_{C O E}$ individually \\
\hline$\mu_{C O E}(\$ / \mathrm{MWh})$ & 52.08 \\
\hline$\sigma_{C O E}(\$ / \mathrm{MWh})$ & 5.02 \\
\hline$\mu$ Energy Output $(\mathrm{MWh} / \mathrm{yr})$ & 74407 \\
\hline$\mu$ Cost Output $(\$ \mathrm{k} / \mathrm{yr})$ & 3835 \\
\hline
\end{tabular}

667 


\begin{tabular}{|c|c|c|c|c|c|c|c|c|c|c|c|c|c|c|c|c|c|c|c|c|c|c|}
\hline 0 & $\phi$ & 0 & 0 & 0 & 0 & 0 & 0 & 0 & 0 & 0 & 0 & $\begin{array}{ll}0 & 0\end{array}$ & 0 & 0 & $\phi$ & 0 & 0 & 0 & 0 & 0 & 00 & \\
\hline 0 & 0 & 0 & 0 & 0 & 0 & 0 & 0 & 0 & 0 & 0 & 0 & 00 & 0 & 10 & 0 & 0 & 0 & 0 & 0 & 0 & 00 & \\
\hline 0 & 0 & 0 & 0 & 0 & 0 & 0 & 0 & 0 & 0 & 0 & 0 & 00 & 0 & 0 & 0 & 0 & 0 & 0 & 0 & 0 & 00 & \\
\hline 0 & 0 & 0 & 0 & 0 & 0 & 0 & 0 & 0 & 0 & 0 & 0 & 00 & 0 & 0 & 0 & 0 & 0 & 0 & 0 & 0 & 00 & \\
\hline 0 & 0 & 0 & 0 & 0 & 0 & 0 & 0 & 0 & 0 & 0 & 0 & 00 & 0 & 0 & 0 & 0 & 0 & 0 & 0 & 0 & 00 & \\
\hline 0 & 0 & 0 & 0 & 0 & 0 & 0 & 0 & 0 & 0 & 0 & 0 & 00 & 0 & 0 & 0 & 0 & 0 & 0 & 0 & 0 & 00 & \\
\hline 0 & 0 & 0 & 0 & 0 & 0 & 0 & 0 & 0 & 0 & 0 & 0 & 100 & 0 & 0 & 0 & 0 & 0 & 0 & 0 & 0 & 00 & \\
\hline 0 & 0 & 0 & 0 & 0 & 0 & 0 & 0 & 0 & 0 & 0 & 0 & 00 & -0 & $\theta$ & -0 & $\theta$ & -0 & 0 & 0 & 0 & 00 & \\
\hline 0 & 0 & 0 & 0 & 0 & 0 & 0 & 0 & 0 & 0 & 0 & 0 & 00 & 0 & 0 & 0 & 0 & 9 & 0 & 0 & 0 & 00 & Potential Turbine \\
\hline 0 & 0 & 0 & 0 & 0 & 0 & 0 & 0 & 0 & 0 & 0 & 0 & 00 & 0 & 0 & 0 & 0 & o & 0 & 0 & 0 & 00 & \\
\hline 0 & 0 & 0 & 0 & 0 & 0 & 0 & 0 & 0 & 0 & 0 & 0 & $\begin{array}{ll}0 & 9\end{array}$ & 0 & -0 & -0 & 0 & -0 & 0 & 0 & 0 & 00 & \\
\hline 이 & 0 & 0 & 0 & 0 & 0 & 0 & 0 & 0 & 0 & 0 & 0 & 100 & o & 0 & 0 & 0 & 0 & 0 & 0 & 0 & 00 & \\
\hline 0 & 0 & 0 & 0 & 0 & 0 & 0 & 0 & 0 & 0 & 0 & 0 & 00 & 0 & 0 & 0 & 0 & 0 & 0 & 0 & 0 & 00 & \\
\hline 0 & 0 & 0 & 0 & 0 & 0 & 0 & 0 & 0 & 0 & 0 & 0 & 00 & 0 & 0 & 0 & 0 & 0 & 0 & 0 & 0 & - $\sigma$ & \\
\hline 0 & 0 & 0 & 0 & 0 & 0 & 0 & 0 & 0 & 0 & 0 & Le & 00 & 0 & 0 & 0 & 0 & 0 & 0 & 0 & 0 & 00 & 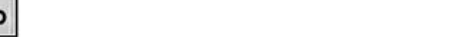 \\
\hline 0 & 0 & 0 & 0 & 0 & 0 & 0 & 0 & 0 & 0 & 0 & 0 & $\begin{array}{ll}0 & 0\end{array}$ & 0 & 0 & 0 & 0 & 0 & 0 & 0 & 0 & 00 & \\
\hline 0 & 0 & 0 & 0 & 0 & 0 & 0 & 0 & 0 & 0 & 0 & 0 & 00 & 0 & 0 & 0 & 0 & 0 & 0 & 0 & 0 & 00 & \\
\hline 0 & 0 & 0 & 10 & 0 & 0 & 0 & 0 & 0 & 0 & 0 & 0 & 00 & 0 & 0 & 0 & 0 & 0 & 0 & 0 & 0 & 00 & 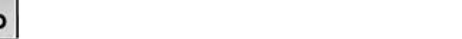 \\
\hline 0 & 0 & 0 & 0 & 0 & 0 & 0 & 0 & 0 & 0 & 0 & 0 & 00 & 0 & 0 & 0 & 0 & 0 & 0 & 0 & 0 & 00 & $\overline{5}$ \\
\hline 0 & 0 & 0 & 0 & 0 & 0 & 0 & 0 & 0 & 0 & 0 & 0 & 00 & 0 & 0 & 0 & 0 & 0 & 0 & 0 & 0 & 00 & \\
\hline 0 & 0 & 0 & 0 & 0 & 0 & 0 & 0 & 0 & 0 & 0 & 0 & 100 & 0 & 0 & 0 & 0 & 0 & 0 & 0 & 0 & 00 & \\
\hline 0 & 0 & 0 & 0 & 0 & 0 & 0 & 0 & 0 & 0 & 0 & 0 & 00 & 0 & 0 & 0 & 0 & 0 & 0 & 0 & 0 & 00 & 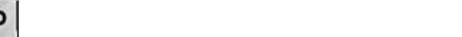 \\
\hline 0 & 0 & 0 & 0 & 0 & 0 & 0 & 0 & 0 & 0 & 0 & 0 & 00 & 0 & 0 & 0 & 0 & 0 & 0 & 0 & 0 & 00 & \\
\hline 0 & 0 & 0 & 0 & 0 & 0 & 0 & 0 & 0 & 0 & 0 & 0 & 00 & 0 & 0 & 0 & 0 & 0 & 0 & 0 & 0 & 00 & \\
\hline
\end{tabular}

669 Figure 7 Test area with 576 instead of 100 potential turbine locations.

670 The optimal layout in Figure 8 (Scenario 1 with 576 potential turbine locations) is

671 different from that in Figure 6 (Scenario 3 with 100 potential turbine locations). One major

672 noticeable change is the shift of turbine from location $\varepsilon$ to $\varepsilon^{\prime}$, as shown in Figure 8. Note

673 that the new turbine location $\varepsilon^{\prime}$ is located on plot 15-1 (the purple plot with black borders),

674 and plot 15-1 only has 3 potential turbine locations for the lower-resolution solution space,

675 as shown in Figure 1. However, in this section, plot 15-1 has 12 potential turbine locations,

676 as shown in Figure 7. The higher-resolution solution space increases the possibility of the

677 optimization algorithm to select small land plots with favorable wind resource and less

678 acquiring cost, such as plot 15-1. 




680 Figure 8 Scenario 1 (minimizing $\mu_{C O E}$ ) with 576 potential turbine locations and Scenario 3

681 (minimizing $\mu_{C O E} \& \sigma_{C O E}$ ) with 100 potential turbine locations have different optimal 682 layouts.

\section{References}

685 Ambrose, S., Rand, R., 2013. Wind Turbine Noise Complaint Predictions Made Easy.

686 Available at: http://www.windaction.org/documents/37241. Accessed on Mar. 26, 2015.

687 Archer, C., and Jacobson, M., 2007. Supplying Baseload Power and Reducing Transmission 688 Requirements by Interconnecting Wind Farms. Journal of Applied Meteorology and 689 Climatology, 46(11), pp. 1701-1717. 
690 Barthelmie, J., Folkerts, L., Rados, K., Larsen, C., Pryor, C., Frandsen, T., Lange, B., Schepers, G., 691 2006. Comparison of wake model simulations with offshore wind turbine wake profiles

692 measured by sodar. Journal of Atmospheric and Oceanic Technology, 23, pp. 888-901.

693 Bolinger, M., and Wiser, R., 2011. Understanding Trends in Wind Turbine Prices Over the

694 Past Decade. LBNL-5119E. Lawrence Berkeley National Laboratory.

695 Carta, J., Ramírez, P., and Vela'zquez, S., 2009. A Review of Wind Speed Probability

696 Distributions Used in Wind Energy Analysis Case Studies in the Canary Islands. Renewable

697 and Sustainable Energy Reviews, 13 (2009), pp. 933-955.

698 Chen, L., 2013. Wind Farm Layout Optimization Under Uncetainty with Landowners'

699 Financial and Noise Concerns. Ph.D. Thesis,Iowa State University, Ames, IA.

700 Chen, L., MacDonald, E., 2015. Wind Farm Layout Optimization Under Uncertainty With

701 Realistic Landowner Decisions. To be submitted to ASME Journal of Energy Resources

702 Technology.

703 Chen, L., MacDonald, E., 2014. A System-level Cost-of-Energy Wind Farm Layout

704 Optimization with Landowner Modeling. Energy Conversion and Management, 77, pp. 484-

705494.

706 Chen, L., MacDonald, E., 2013. Effects of Uncertain Land Availability, Wind Shear, and Cost

707 On Wind Farm Layout. Paper presented at the ASME 2013 International Design Engineering

708 Technical Conferences \& Computers and Information in Engineering Conferences, Portland,

709 Oregon.

710 Chen, L., MacDonald, E., 2012. Considering Landowner Participation in Wind Farm Layout

711 Optimization. Journal of Mechanical Design, 134(8), 084506-084506.

712 Dai, K., Bergot, A., Liang, C., Xiang, W.-N., and Huang, Z., 2015, "Environmental issues

713 associated with wind energy - A review", Renewable Energy, 75, pp. 911-921.

714 Davis, L., 1991, Handbook of Genetic Algorithms, Van Nostrand Reinhold Co., New York, NY.

715 DuPont, B., Cagan, J., 2012. An Extended Pattern Search Approach to Wind Farm Layout

716 Optimization. Journal of Mechanical Design, 134(8), 081002-081018. 
717 Erdem, E., Shi, J., 2011. Comparison of Bivariate Distribution Construction Approaches for

718 Analysing Wind Speed and Direction Data. Wind Energy, 14 (2011), pp. 27-41.

719 Fagerfjäll, P., 2010. Optimizing Wind Farm Layout: More Bang for the Buck Using Mixed

720 Integer Linear Programming. Chalmers University of Technology and Gothenburg

721 University.

722 Fingersh, L., Hand, M., and Laxson, A., 2006. Wind Turbine Design Cost and Scaling Model.

723 Technical Report: NREL/TP-500-40566. National Renewable Energy Laboratory.

724 Grady, S., Hussaini, M., Abdullah, M., 2005. Placement of Wind Turbines Using Genetic

725 Algorithms. Renewable Energy, 30(2), pp. 259-270.

726 Groth, T. M., Vogt, C., 2014. Residents' perceptions of wind turbines: An analysis of two

727 townships in Michigan. Energy Policy, 65(0), pp. 251-260.

728 Houck, C., Joines, J., and Kay, M., 1995. A Genetic Algorithm for Function Optimization: a

729 Matlab Implementation. Technical Report: NCSU-IE-TR-95- 09, North Carolina State

730 University, Raleigh, NC.

731 Iowa Environmental Mesonet, 2013a. "Custom Wind Roses," Iowa State University

732 Department of Agronomy, available at

733 http://mesonet.agron.iastate.edu/sites/dyn windrose.phtml?station=AMW\&network=IA A

$734 \quad$ SOS. Accessed on Oct. 28, 2013.

735 Iowa Environmental Mesonet, 2013b. "ASOS/AWOS Data Download," Iowa State University

736 Department of Agronomy, available at

737 http://mesonet.agron.iastate.edu/request/download.phtml?network=IA ASOS. Accessed

738 on Oct. $28,2013$.

739 ISO 9613-2, 1996. Acoustics - Attenuation of sound during propagation outdoors -Part 2:

740 General method of calculation.

741 Jensen, N., 1983. A Note on Wind Generator Interaction. Risø National Laboratory. DK-4000

742 Roskilde, Denmark. 
743 Katsigiannis, Y., Georgilakis, P., Karapidakis, E., 2012, "Hybrid simulated annealing-tabu 744 search method for optimal sizing of autonomous power systems with renewables," IEEE

745 Transactions on Sustainable Energy, Vol. 3, No. 3, pp. 330-338.

746

747

748

Kusiak, A., and Song, Z., 2010. Design of Wind Farm Layout for Maximum Wind Energy Capture. Renewable Energy, 35(3), pp. 685-694.

749 Kwong, W., Zhang, P., Romero, D., Moran, J., Morgenroth, M., Amon, C., 2012. Multi-objective 750 Optimization of Wind Farm Layouts under Energy Generation and Noise Propagation. Paper 751 presented at the ASME 2012 International Design Engineering Technical Conferences \& 752 Computers and Information in Engineering Conference, Chicago.

753 Lackner, M., and Elkinton, C., 2007. An Analytical Framework for Offshore Wind Farm 754 Layout Optimizaiton. Wind Engineering 31(1), pp. 17-31.

755

756

757

758

759

760

761

762

763

764

765

766

767

768

769

770

771

772

Lambert, T., Gilman, P., and Lilienthal, P., 2006, "Micropower system modeling with HOMER," in Integration of Alternative Sources of Energy, F. A. Farret and M. G. Simões, Eds. Hoboken, NJ: Wiley, pp. 379-418.

Marmidis, G., Lazarou, S., Pyrgioti, E., 2008. Optimal Placement of Wind Turbines in a Wind Park Using Monte Carlo Simulation. Renewable Energy, 33(7), pp. 1455-1460.

Morgan, E., Lackner, M., Vogel, R., and Baise, L., 2011. Probability Distributions for Offshore Wind Speeds. Energy Conversion and Management, 52 (2011), pp. 15-26.

Mosetti, G., Poloni, C., Diviacco, B., 1994. Optimization of Wind Turbine Positioning in Large Windfarms by Means of a Genetic Algorithm. Journal of Wind Engineering and Industrial Aerodynamics, 51(1), pp. 105-116.

Mosman, K., 2015, "Wind Farm A Good Neighbor," available at: http://www.oleantimesherald.com/editorial/article f74dc548-69ca-11e0-b1ae00.1cc4c002e0.html. Accessed on Mar. 26, 2015.

Muschell, K., 2015. "BP Good Neighbor Recruiting Letter," available at: http://pandorasboxofrocks.blogspot.com/2013/01/bp-good-neighbor-recruitmentletter.html. Accessed on Mar. 26, 2015.

Office of Energy Efficient and Renewable Energy, 2015a, "Renewable Energy Generation," availble at: http://energy.gov/eere/renewables. Accessed on Mar. 26, 2015 
773 Office of Energy Efficient and Renewable Energy, 2015b, "Soft Cost," available at:

774 http://energy.gov/eere/sunshot/soft-costs. Accessed on Mar. 26, 2015.

775 Ozturk, U., and Norman, B., 2004. Heuristic Methods for Wind Energy Conversion System

776 Positioning. Electric Power Systems Research, 70(3), pp. 179-185.

777 Pedersen, E., Waye, K., 2007. Wind Turbine Noise, Annoyance and Self-Reported Health and 778 Well-Being in Different Living Environments. Occupational and Environmental Medicine, 779 64(7), pp. 480-486.

780 Ray, M., Rogers, A., and McGowan, J., 2006. Analysis of Wind Shear Models and Trends in 781 Different Terrain. Conference Proceeding: American Wind Energy Association

782 Windpower. Pittsburgh, PA, June 2-7.

783 Songsore, E., Buzzelli, M., 2014. Social responses to wind energy development in Ontario: 784 The influence of health risk perceptions and associated concerns. Energy Policy, 69(0), pp. $785 \quad 285-296$.

786

787

788

789

790

791

792

793

794

795

796

797

798

799

800

801

Sorkhabi, S. Y. D., Romero, D. A., Yan, G. K., Gu, M. D., Moran, J., Morgenroth, M., and Amon, C. H., 2016, "The impact of land use constraints in multi-objective energy-noise wind farm layout optimization", Renewable Energy, 85, pp 359-370.

Takle, E., Lundquist, J., 2011. Research Experience for Undergraduates: Crop-Wind-EnergyExperiment (C-WEX), available at: http://www.eol.ucar.edu/about/ourorganization/fps/observing-facilities-assesment-panel-ofap/educational-facilityrequests/edu CWEX 2011 complete.pdf.

The Associated Press. "Oregon Man Files \$5 Million Suit over Wind Farm Noise," available at: http://www.oregonlive.com/pacific-northwestnews/index.ssf/2013/08/post 133.html, accessed on Mar. 26, 2015.

U.S. Energy Information Administration, "Levelized Cost and Levelized Avoided Cost of New Generation Resources in the Annual Energy Outlook 2014," available at: http://www.eia.gov/forecasts/aeo/pdf/electricity generation.pdf. Accessed on Mar. 26, 2015.

Wall, M., 1999. GAlib: a C++ Library for Genetic Algorithm Components, available at: http://lancet.mit.edu/ga/Copyright.html: Massachusetts Institute of Technology. 
802 Wikipedia, 2013. "Story County Wind Farm." Available at:

803 http://en.wikipedia.org/wiki/Story County Wind Farm. Accessed on Mar. 26, 2015.

804 Windustry, 2009, "Wind Energy Easement and Leases: Compensation Packages," Windustry

805 Wind Easement Work Group, available at:

806 http://saline.unl.edu/c/document library/get file?folderId=294039\&name=DLFE-

807 18538.pdf, accessed on Oct. 28, 2013.

808 Zhang, J., Chowdhury, S., Messac, A., and Castillo, L., 2011. Multivariate and Multimodal

809 Wind Distribution Model Based on Kernel Density Estimation. ASME 2011 5th International

810 Conference on Energy SustainabilityWashington, DC, USA.

811

812 